\title{
Self-Selected Individual Music Therapy for Depression during Hospitalization for Cancer Patients: Randomized Controlled Clinical Trial Study
}

\author{
Widiyono ${ }^{1}$, Sri Setiyarini ${ }^{2}$, Christantie Effendy ${ }^{3}$ \\ ${ }^{1}$ Medical-Surgical Nursing Department, School of Nursing, ScienceTechnology and Health Faculty, Sahid Surakarta University \\ 2 Basic and Emergency Nursing Department, School of Nursing, Medicine Faculty, Universitas Gadjah Mada \\ ${ }^{3}$ Medical-Surgical Department, School of Nursing, Medicine Faculty, Universitas Gadjah Mada
}

\section{ARTICLE INFO}

Received : 18 March 2019

Reviewed : 2 June 2019

Accepted : 27 September 2019

\section{Keywords:}

cancer, complementary and alternative medicine (CAM), depression, music therapy.

*Corresponding author:

Widiyono

School of Nursing, ${ }^{2}$ nd Floor,

Sains Technology and Healthy Faculty,

Sahid Surakarta University.

Adi Sucipto 154, Jajar, Laweyan, Solo.

widiyono2727@gmail.com

\author{
A BSTRACT
}

Background: Depression is a psychological distress that often occurs on cancer patients. Depression can increase patient perception about pain, resulting reduced drug efficacy and longer length of stay. Drug treatment for depression sometimes has side effects. Another intervention to decrease depression on cancer patients is music therapy. Music therapy might avoid polypharmacy in cancer patients. The purpose of this study was to determine the effects of self-selected individual music therapy toward depression of cancer patients.

\begin{abstract}
Methods: The method used in this study was the randomized control trial (RCT). Simple Random Sampling was assigned randomly by three researcher assistants to participants $(N=70)$ of intervention and control group. The intervention used was self-selected individual music therapy (SeLIMUT). SelIMuT was applied four times in 2 days with a duration of 15 minutes each session. Beck Depression Inventory (BDI) was employed for selection purposes. The data were analyzed using Mann-Whitney with $p<0.05$ and $95 \% \mathrm{Cl}$. The effectiveness of therapy was analyzed by the effect size test using abs $r$.
\end{abstract}

Results: Based on the result of the bivariate analysis, there was an effect of giving self-selected individual music therapy to reduce depression with depression gap in both groups with $p$-value of $0.001(p<0.05)$. The value of the effect test obtained abs $r=0.82(r>0.5)$. At the end, the self-selected individual music therapy had moderate effect toward depression of cancer patients.

Conclusions: Music therapy is safe, inexpensive, and easy to use, for and by patients. The nurse can safely recommend any of these interventions for depression on cancer patients. Specific selections or types of music may have different effects on different patients and may provide different effects at different time, so the use of self-selected individual music therapy is recommended.

\section{INTRODUCTION}

Cancer incidence in the world increases from 12.7 million to 14.1 million cases from 2008 to 2012. World Health Organization (WHO) mentioned two-thirds of new cancer-related cases are always in countries with lowto-middle social economies [1]. Cancer is a lifethreatening disease as the condition of prognosis often worsens [2]. This disease has a serious impact on the quality of life of a person. The patients often experiences physical, psychosocial, spiritual and other problems [3]. Psychosocial issues consist of anxiety, fear of undergoing treatment, relapse, and depression [4-5].

Severe depression is estimated to occur in $16 \%$ to $25 \%$ of cancer patients [6]. The study result of Effendy et al. [3] in 2014 showed that $34.4 \%$ of cancer patients in Indonesia were depressed. The increase of depression is in accordance with the occurrence of disability and widespread stage of cancer [3-7]. Depression improved patient perception towards pain, reducing drug efficacy and longer length of stay in the hospital and encouraging suicide [8].

Observing the adverse effects of depression on the prognosis of disease, the depression management is important in preparation of intervention for cancer patients [9-10]. Sometimes drug treatment has a side effects on cancer patients [11]. The use of Complementary and Alternative Medicine (CAM) in the treatment of cancer patients has increased lately. Globally, over $80 \%$ of cancer patients have used some types of CAM therapies [10-12].

Music therapy can indeed exert a positive effect of psychological support like depression, whereas no 
adverse effects of music therapy have been reported so far [13]. The use of music therapy on depression of cancer patients might avoid the polypharmacy [11]. Music therapy is one form of CAM that can be used to overcome depression in cancer patients [9-14]. It has the advantage to be applied in a simple therapy and cost-effective because the price is affordable and the therapy is non-invasive, does not require a therapist and does not cause side effects [15].

Music therapy will be more effective if the individual chooses his own preferred type of music [16-17]. Selfselected individual music therapy is the planned use of music to achieve therapeutic outcomes combined with deep breath and the kind of song is chosen by the patient. This study aimed to evaluate the effect of self-selected individual music therapy toward depression of cancer patients. The reasons above, make the researcher use the self-selected music therapy as a complementary therapy for cancer patients in overcoming depression.

\section{METHODS}

\section{Design}

This study utilized a randomized controlled trial study. Music therapy sessions took place in participants' rooms on the oncology unit after completing a pre-test. Data collection was conducted in inpatient unit I of Dr. Sardjito Hospital in Yogyakarta and Bougenvile-Teratai unit of Prof. Dr. Margono Soekarjo Hospital in Purwokerto, Central Java, Indonesia. Data collection occurred from March until May 2017. The patients were recruited if they complied with inclusion criteria, agreed to be the participant, and had signed the inform consent. The intervention group was given self-selected individual music therapy (SeLIMUT) after measurement of depression on pre-test while the control group was given the treatment after the study had been complete (after finishing the post-test).

\section{Research Participant}

Sampling was done by non-probability sampling with purposive sampling technique. Inclusion criteria for this study were patients diagnosed with cancer, depressed (BDI > 9), who like music and did not experience hearing loss. Exclusion criteria were patients in emergency, listening music more than 20 minutes every day, using anxiolytic drugs (such as thiopentyl and flumazenil) and antidepressants. The number of samples was 70 respondents.

The screening process was conducted to determine the respondents who met the criteria and a simple randomization process was done to determine the respondents into either the intervention or control group. Simple random sampling was assigned by anonymizing participants and using a random number table to distribute participants into either group: intervention group $(n=35)$ and control group $(n=35)$. This study used single-blind. The subjects were not informed about the allocation. Subjects in the intervention group had access to this information.

\section{Instruments}

The instrument used in the study was Beck Depression Inventory (BDI) to measure the level of depression experienced by cancer patients [18]. Beck Depression Inventory is a self-rating assessment and was used to evaluate the intensity of depressive symptoms based on the patient's perception. Depression assessment of 0 to 9 indicates normal, 10 to 15 mild depression, 16 to 23 moderate depression, and 24 to 63 severe depression. It is considered significantly different if there is a difference in the average depression of 5 points between before and after intervention.

\section{Procedure}

Self-selected individual music therapy was a procedure of providing music therapy with slow music criteria, stable tempo, soft dynamic, and consistent texture chosen according to the patient's preferences, combined with a deep breath. Intervention therapy was applied four times in 2 days with duration about 15 minutes each session and the patient could listen to music through MP3 Player and headphones. Selfselected individual music therapy was given to patients in both groups. For the control group, music therapy was given after the post-test had been performed.

The intervention was given in the afternoon to avoid interfering with the activities of the fixed procedure of treatment in the room, so the patient would feel more comfortable in doing music therapy. Before given music therapy, the author(s) checked the general state, vital signs and complaints of patients to avoid the side effects that might be caused by the music therapy like headaches and ears drooped.

To minimize the bias of this study, the author(s) made the data sample homogeneity with inclusion criteria. This study was approved by the Ethics Committee of the Medicine Faculty of Universitas Gadjah Mada with Ethical Clearance number of REF: KE/ FK/0150/EC/2017.

\section{Statistical Analysis}

The characteristics of demography data were categorical by the homogeneity test with Chi-Square or Fisher Exact. The mean differences of the depression 
rates between the pre- and post-intervention of both groups ( $n=35$ on each group) were tested for normality with Shapiro-Wilk test and the results were not normally distributed, so the data were analyzed using Mann-Whitney with $\mathrm{p}<0.05$ and $95 \% \mathrm{Cl}$. The effectiveness of the therapy was performed by the effect size test using abs $r$.
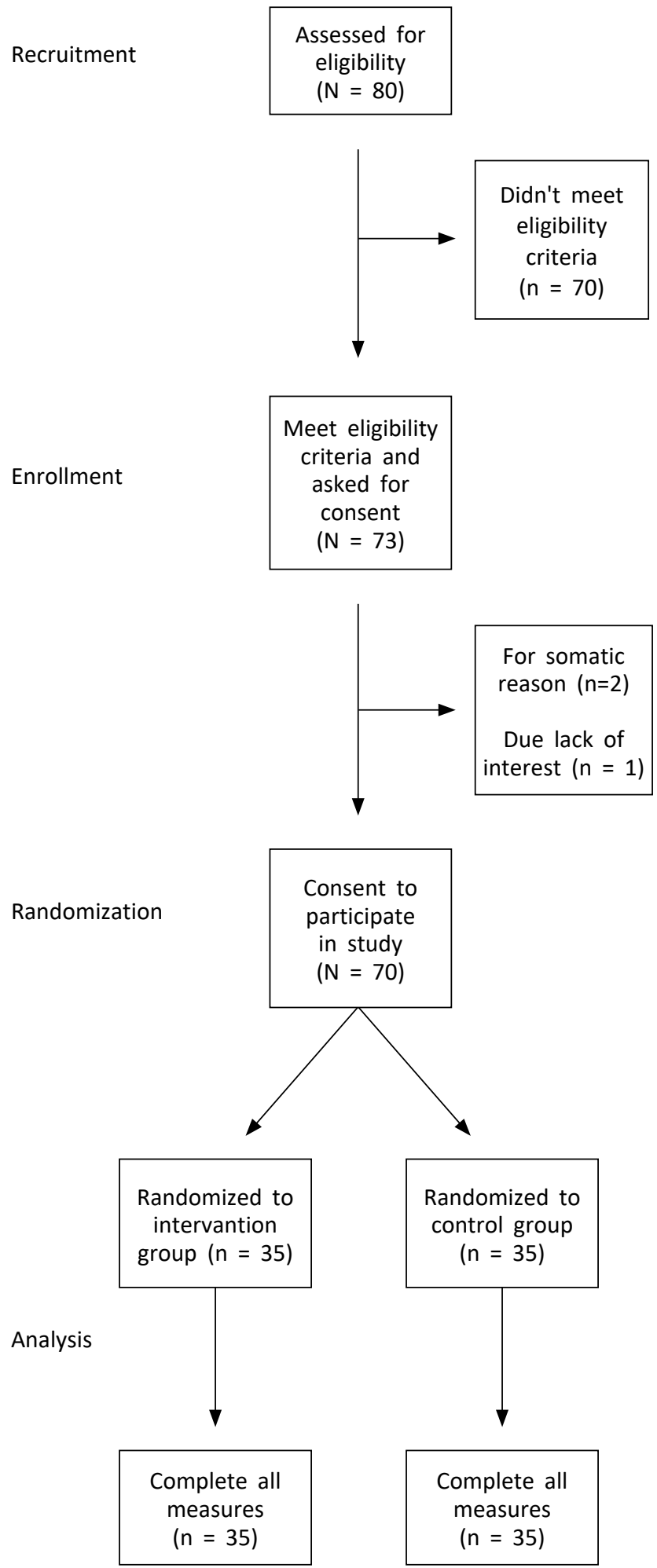

Figure 1. Assessment for eligibility criteria

\section{RESULTS}

The demographic data of the respondents were divided to demographics and health condition of the respondents. Both intervention groups were compared with the control group (Table 1). The homogeneity of the demographic data in both groups showed that there was no significant difference. This means that the characteristics of the respondents of both groups are homogeneous or the same.

Table 1. Demographic characteristics $(n=70)$.

\begin{tabular}{|c|c|c|}
\hline \multirow{3}{*}{ Characteristics } & \multicolumn{2}{|c|}{ Group } \\
\hline & $\begin{array}{c}\text { Intervention } \\
(\mathrm{n}=35)\end{array}$ & $\begin{array}{l}\text { Control } \\
(n=35)\end{array}$ \\
\hline & $f(\%)$ & $f(\%)$ \\
\hline \multicolumn{3}{|l|}{ Gender/Sex } \\
\hline Female & $26(74.3)$ & $25(71.4)$ \\
\hline Male & $9(25.7)$ & $10(28.6)$ \\
\hline \multicolumn{3}{|l|}{ Age } \\
\hline $\begin{array}{l}\text { Early adulthood } \\
\text { (20-40 years) }\end{array}$ & $5(14.3)$ & $7(20.0)$ \\
\hline $\begin{array}{l}\text { Mature adults } \\
\text { ( }>40-60 \text { years) }\end{array}$ & $26(74.3)$ & $25(71.4)$ \\
\hline $\begin{array}{l}\text { The final adult } \\
\text { ( }>60 \text { years) }\end{array}$ & 4 (11.4) & $3(8.6)$ \\
\hline \multicolumn{3}{|l|}{ Education level } \\
\hline Elementary school & $24(68.6)$ & $19(54.3)$ \\
\hline Junior high school & $5(14.3)$ & $8(22.9)$ \\
\hline Senior high School & $4(11.4)$ & $4(11.4)$ \\
\hline Diploma & $0(0)$ & $3(8.6)$ \\
\hline Bachelor & $2(5.7)$ & $1(2.9)$ \\
\hline \multicolumn{3}{|l|}{ Marital status } \\
\hline Married & $29(82.8)$ & $34(87.1)$ \\
\hline Widow & $6(17.2)$ & $1(2.9)$ \\
\hline \multicolumn{3}{|l|}{ Work } \\
\hline Housewife & $11(31.4)$ & $12(34.3)$ \\
\hline Entrepreneur & $5(14.3)$ & $10(28.6)$ \\
\hline Civil servant & $4(11.4)$ & $7(20.0)$ \\
\hline Private & $2(5.7)$ & $0(0.0)$ \\
\hline Farmers & $13(37.3)$ & $6(17.1)$ \\
\hline
\end{tabular}

According to Table 2, the homogeneity of the health condition data in both groups showed that there was no significant difference. This means that the characteristics of the health condition respondents of both groups are homogeneous or the same. 
Table 2. Health condition $(n=70)$

\begin{tabular}{lcc}
\hline \multirow{2}{*}{ Characteristics } & \multicolumn{2}{c}{ Group } \\
\cline { 2 - 3 } & $\begin{array}{c}\text { Intervention } \\
(n=35)\end{array}$ & $\begin{array}{c}\text { Control } \\
(n=35)\end{array}$ \\
\cline { 2 - 3 } & $f(\%)$ & $f(\%)$ \\
\hline
\end{tabular}

Cancer types

$\begin{array}{lcc}\text { Breast } & 12(34.2) & 10(28.6) \\ \text { Rectum } & 7(20.0) & 2(5.7) \\ \text { Cervix } & 6(17.1) & 3(8.6) \\ \text { Ovary } & 3(8.6) & 3(8.6) \\ \text { Colon } & 2(5.8) & 4(11.4) \\ \text { Colli/Tiroid } & 1(2.9) & 3(8.6) \\ \begin{array}{l}\text { Other (femur, pedis testis, } \\ \text { lung, nasopharynx, } \\ \text { mandible) }\end{array} & 4(11.4) & 10(28.6)\end{array}$

Duration of illness

$\begin{array}{lcc}<2 \text { year } & 22(62.8) & 24(68.6) \\ 2-5 \text { year } & 10(28.6) & 8(22.9) \\ >5 \text { year } & 3(8.6) & 3(8.6)\end{array}$

Type of therapy

$\begin{array}{lcc}\text { No treatment } & 2(5.7) & 2(5.7) \\ \text { Surgery } & 7(20.0) & 11(31.4) \\ \text { Chemotherapy } & 3(8.6) & 2(5.7) \\ \text { Radiotherapy } & 2(5.7) & 0(0.0) \\ \text { Surgery \& Chemotherapy } & 16(45.7) & 19(54.3) \\ \text { Surgery \& Radiotherapy } & 0(0.0) & 1(2.9) \\ \begin{array}{l}\text { Surgery, Chemotherapy, } \\ \text { \& Radiotherapy }\end{array} & 5(14.3) & 0(0.0)\end{array}$

Comorbid disease

$\begin{array}{lcc}\text { No comorbid disease } & 27(77.1) & 26(74.3) \\ \text { Anemia } & 3(8.6) & 3(8.6) \\ \text { DM } & 2(5.7) & 2(5.7) \\ \text { Asthma } & 2(5.7) & 2(5.7) \\ \text { Hypertension } & 0(0.0) & 2(5.7) \\ \text { Hepatitis } & 1(2.9) & 0(0.0) \\ \text { Smoking } & 7(20.0 \%) & 8(22.9) \\ \text { Yes } & 28(80.0 \%) & 27(77.1) \\ \text { No } & & \\ \text { Alcohol consumption } & 1(2.9) & 0(0.0) \\ \text { Yes } & 34(97.1) & 35(100) \\ \text { No } & & \end{array}$

The depression conditions of the respondents in this study can be known from the results of BDI. Based on the results of BDI's first measurements in both groups $(n=70)$, the majority of respondents answered that they postpone making decisions (45.7\%), they felt that they might be punished (50\%), they felt sad (64.3\%), they felt they could not enjoy everything as usual (57.1\%), they cried more than usual $(57.1 \%)$, they were more easily irritated or angry (57.1\%), they were awakened two to three hours early and they had difficulty sleeping back (48.6\%), their appetites were not as big as usual (47.1\%) and they were anxious about their physical health such as pain (54.3\%).

The depression condition in the intervention group changed after SeLIMUT. Based on the results of BDI's last measurements in the intervention group $(n=35)$, the majority of respondents answered that their making decisions was better than before $(51.4 \%)$, they did not feel that they were being punished (34.3\%), they did not feel sad (48.6\%), they felt satisfied with everything $(51.4 \%)$, they did not cry more than usual $(60 \%)$, they did not feel more irritated than before $(82.9 \%)$, they could sleep soundly $(28.6 \%)$, their appetites were as usual (28.6\%), and they did not worry about their health beyond the usual (42.9\%). The depression condition in the last measurements on the control group $(n=35)$ had the same result compared with the first measurements.

According to Table 3, the mean difference in the pre-post depression rates of the intervention group $(n=35)$ result in $p$-value $0.001(p<0.05)$ showed significant depression difference before and after SelIMut in intervention groups. While in the control group $(n=35)$, result in $p$-value 0.196 ( $p>0.05$ ) showed no significant depression difference in the first and last measurements in the control group.

Table 3. Mean difference depression on each group $(n=35)$

\begin{tabular}{|c|c|c|c|c|}
\hline \multirow[b]{2}{*}{ Group } & \multicolumn{4}{|c|}{ Difference value on each group } \\
\hline & $\begin{array}{c}\text { Med. } \\
\text { (min-max) }\end{array}$ & $\begin{array}{l}\text { Mean } \\
\text { Rank }\end{array}$ & p-value & $95 \% \mathrm{Cl}$ \\
\hline $\begin{array}{l}\text { Intervention } \\
(n=35)\end{array}$ & & & $0.001^{* c}$ & \\
\hline Pre-test & $\begin{array}{c}20.0 \\
(13.0-34.0)\end{array}$ & 00.0 & & 20.1-23.9 \\
\hline Post-test & $\begin{array}{c}13.0 \\
(2.0-23.0)\end{array}$ & 18.0 & & 11.4-14.6 \\
\hline $\begin{array}{l}\text { Control } \\
(n=35)\end{array}$ & & & $0.196^{d}$ & \\
\hline Pre-test & $\begin{array}{c}17.0 \\
(10.0-4.0)\end{array}$ & 16.1 & & $16.4-21.8$ \\
\hline Post-test & $\begin{array}{c}16.0 \\
(11.0-5.0)\end{array}$ & 11.2 & & $17.2-22.7$ \\
\hline
\end{tabular}

* significant $(\mathrm{p}<0.050), \mathrm{d}$ analysis using Wilcoxon 
Table 4. Mean difference of depression on two groups $(n=70)$

\begin{tabular}{|c|c|c|c|c|c|c|c|}
\hline \multirow{2}{*}{ Groups } & \multicolumn{7}{|c|}{ Difference value on both groups } \\
\hline & Med. (min-max) & Mean Rank & p-value & $\mathbf{U}$ & $\mathbf{Z}$ & $\mathbf{r}$ & $95 \% \mathrm{Cl}$ \\
\hline Intervention ( $\mathrm{n}=35$ ) & $\begin{array}{c}8.0 \\
(3.0-31.0)\end{array}$ & 18.0 & & & & & $7.2-10.7$ \\
\hline Control (n = 35) & $\begin{array}{c}0.0 \\
(-13.0-9.0)\end{array}$ & 52.0 & $0.001^{* d}$ & 28.0 & -6.8 & $0.8^{e}$ & $-2.1-0.5$ \\
\hline
\end{tabular}

*significant ( $p<0.05$ ), d analysis using Mann-Whitney, e analysis ES using abs $r$

According to Table 4, the pre-post depression gap in both groups obtained $p$-value 0.001 ( $p<0.05)$ which means there is a significant effect of giving self-selected individual music therapy to reduce depression. The effect test obtained abs $r=0.82(r>0.5)$ indicating that music therapy has a severe effect on depression decrease.

\section{DISCUSSION}

Based on the results of the screening, it was shown that all cancer patients who were treated in oncology unit suffered from depression. The results showed that SeLIMUT had an effect on depression both statistically and clinically. Significant effect of self-selected individual music therapy administration on depression reduction can be seen in Table 4, which obtained value difference between pre- and post-depression in both groups with a $p$-value of 0.001 ( $p<0.05)$.

Self-selected individual music therapy has a moderate effect on reducing depression in cancer patients. The effect test resulted in absolute $r$ test (abs $r$ ) of 0.82 $(r>0.5)$. The result of this effect size is higher than the study of Romito et al. [19] which got the result of $d=0.52$. This suggests that music has a moderate effect on decreasing depression. Different effect sizes in this study may be due to music administration duration, wherein Romito et al. [19] study music therapy was given only once (single session) when the patients were undergoing chemotherapy.

The positive impact of self-selected individual music therapy to decrease depression in this study can be explained by the fact that self-selected individual music therapy can reduce stress, improve mood, overcome changes in motor function and behavior, and increase relaxation.

Stress is associated with the incidence of depression and will result in dysregulation of the Hypothalamic Pituitary Adrenal (HPA) Axis that causes changes in serotonin metabolism and negatively affects cognitive control in the frontal lobes of the brain, causing damage to the hippocampus and decreased dopaminergic function [20-21]. The stress caused a decrease in cognitive abilities, difficulty in concentrating, decision making, getting easily confused, impaired memory, feeling of guilt or regret and lack of self-esteem [22-23]. Stress can be observed from the result of BDI of the respondents of both groups in the last measurement showing that the respondents postponed making decisions and felt that they might be harvested.

Stress is related to patients' condition during hospitalization. They said that the stress was caused by their illness and the feeling of boredom due to monotonous activities such as being examined by healthcare personnel, taking medication, eating diet foods from the hospital, and resting on the bed. The state of stress in cancer patients is associated with the incidence of depression [24]. Stress conditions due to undergoing treatment will make cancer patients think of the perceived depression more acutely [25].

In the intervention group of respondents, after being given self-selected individual music therapy, the majority answered that they made decision better than before and did not feel punished. The phenomenon can be explained by the fact that music has a component of tone and rhythm that can give a psychological effect on the listener [26-27]. Electromagnetic wave-shaped sound stimulation from music therapy will vibrate the eardrum and pass to the central nervous system precisely on the limbic system that functions as neurophysiology associated with feelings, memory, sensation, and motivation [28-29]. This result is similar to Jia et al. [10] that music intervention can improve the emotion of cancer patients during disease progression.

Based on the result of $\mathrm{BDI}$ response of the initial measurement in both groups, the majority of respondents answered that they were feeling sad, could not enjoy everything as usual, cried more than usual, and were more easily annoyed or angry. According to Nevid et al. [22], one of the common characteristics of depression is a change in mood conditions of feeling down, sad or cheap, crying more frequently and increased irritability. The symptoms of depression are included in affective manifestations [18].

Self-selected individual music therapy is able to decrease the symptoms of depression that include those 
affective manifestations. Based on the result of the last BDI measurement in the intervention group showing that the majority of respondents said that they did not feel sad, felt satisfied on everything, did not cry more often than usual and did not feel more easily irritated than before. The change can be explained by the fact that once the music sound stimulates the limbic system, the music will call the memory or deep memories of the patients resulting in mood changes and can make a therapeutic effect by decreasing the depression in patients [30].

Besides, music can also cause effects of pleasure or euphoria for those who listen [31]. This effect is equivalent to consuming caffeine and alcohol [32-33]. The happy or cheerful feelings can reduce the levels of cortisol, epinephrine, and norepinephrine because the music that has entered the pituitary gland is able to respond to the emotion through negative feedback to the adrenal gland to suppress the release of the hormone [34]. The cheerful feeling was observed in the intervention group respondents who participated in singing some memorized lyrics, moving the toes and moving the wrists as the self-selected individual music therapy process progresses.

The last BDI measurements showed that the majority of respondents in both groups answered they woke up two to three hours earlier and were having difficulty to sleep again and the appetite was not as great as usual. The symptoms of depression are included in vegetative and physical manifestations [18]

In contrast to the non-intervention group, after getting self-selected individual music therapy, the majority of the intervention group respondents answered that they could sleep as soundly as usual and had normal appetite. The changes in the symptoms of depression indicated that music therapy is a unique application to enhance personal that may create positive changes in one's behavior [35]. Changes to those conditions can be explained by the fact that the sound waves issued by music could generate alpha waves [36]. Alpha waves are created in the cerebral cortex through a cortical relationship with the thalamus and are the result of spontaneous feedback of oscillations in the thalamocortical system causing an increase of serotonin, which is a neurotransmitter responsible for hunger and generating theta waves associated with mental activity, as well as delta waves associated with drowsiness [36-37]. It was observable in the intervention group because the respondents seemed to close their eyes because they were feeling comfortable, and some even fell asleep during the intervention.

The preliminary BDI measurement results showed that the majority of respondents in both groups were feeling anxious about their physical health for having problems such as getting sicker and pain, stomachache, or constipation. Symptoms of such psychosomatic depression include the categories of vegetative and physical manifestations [18]. The pain will have an impact on anxiety and depression [38].

After obtaining self-selected individual music therapy, the majority of respondents in the intervention group did not worry about their health beyond the usual. It is supported by another study conducted by Romito et al. [19] that mentioned music therapy could reduce psychological discomfort like anxiety.

Self-selected individual music therapy mechanism in enhancing relaxation can be explained by the fact that the stimulus of music will form a perfect alpha wave and stimulate the release of the neurotransmitter serotonin which will be converted into melatonin and provides a relaxing effect that can reduce depression $[11,28,36,37]$. This audio stimulus also affects the pituitary in the brain to produce endorphins that can reduce feelings of anxiety [39].

The limitation of this study is that the stage of cancer was not examined because it was not recorded in the medical record and the authors did not check the surgical oncologist because of the limited time. However, the study has looked at the general condition of the cancer patients prior to music therapy, both in the intervention and control groups.

\section{CONCLUSIONS}

Music therapy is safe, inexpensive, and easy to use, for and by patients. The nurse can safely recommend any of these interventions for depression on cancer patients. Specific selections or types of music may have different effects on different patients and may provide different effects at different time, so the use of selfselected individual music therapy is recommended.

\section{DECLARATIONS}

\section{Competing of Interest}

There is no conflict of interest in this study.

\section{Acknowledgment}

The authors thank our colleagues from SeLIMuT Team who provided insight, expertise that greatly assisted the study, for their assistance with a particular technique and for comments that greatly improved the manuscript. 


\section{REFERENCES}

1. International Agency for Research on Cancer (IARC). Latest world cancer statistics: Extimated Cancer Incidence. 2013;Access on 18 Sept. 2016.

2. Smeltzer SC, Bare BG, Hinkle JI, Cheever, KH. Brunner and Suddarth's Textbook of Medical Surgical Nursing. Ed. Philadelphia: Lippincott Williams and Wilkins. 2008; $11^{\text {th }}$ rev.

3. Effendy C, Vissers K, Osse BH, Tejawijaya S, VernooijDagsen $M$, Engels $Y$. Comparison of problems and unmet needs of patients with advanced cancer in a European country and an Asian country. Pain Pract. 2014;(5): 433-440.

4. Whitmer KM, Pruemer JM, Nahleh ZA, Jazieh AR. Symptom management needs of oncology outpatients. J Palliat Med. 2006;9(3): 628-30.

5. American Cancer Society (ACS). Caring for patient with cancer at home: A guide for patients and families. Atlanta: American Cancer Society. 2015.

6. Miller G. Cancer prevention and treatment. $5^{\text {th }} \mathrm{Ed}$. Jakarta: Pustakaraya. 2008

7. Koningan A. Depression on cancer paliative care Paliative center care and pain free on Dr. Soetomo Surabaya Hospital. Available from http: www. Paliative.surabaya.com. 2008; Acces on 21 July 2016.

8. Chintamani C, Gogne A, Khandelwal R, Tandon M, Jain S, Kumar $\mathrm{Y}$, Narayan N, et al. The correlation of anxiety and depression levels with response to neoadjuvant chemotherapy in patients with breast cancer. JRSM Short Report. 2011;2(3): 1-15.

9. Boehm K, Cramer H, Staroszynski T, Ostermann T. Arts therapies for anxiety, depression, and quality of life in breast cancer patients: A systematic review and meta-analysis. Evid Based Complement Alternat Med. 2014; 1-9.

10. Jia L, Chen J, Th Ho R, Yu J, Guo L, Li L. Music intervention can improve emotional in cancer patients during disease progression. Arch Deppres Anxiety. 2016;2(1): 007-009.

11. Purbowinoto SE, Kartinah. Effects music therapy on geriatic depression Yogyakarta. Scientific Publication UMS. 2011; 4: 44-49.

12. Abigail M, Qin L, Bauver-Wu S. Prevalence and predictor of complementary therapy use in advancedstage breast cancer patients. J Oncol Pract. 2007;3(6): 292-95.

13. Edwards J. Music therapy in the treatment and management of mental disorders. Ir J Psychol Med. 2006;22: 33-35.

14. Hawks J, Moyad M. CAM: Definition and Classification. Overview. Urologic Nursing. 2003;23(3): 221-223.

15. Samuel, H. Effects mozart and music therapy in health care. 2007; Available from http://www.tempo.co.id/ medika/arsip/012003/pus-2.htm. Acces on 21 July 2016.
16. Salamon E, Bernstein SR, Kim S, Kim M, Stefano GB. The effect of auditory perception and musical preference on anxiety in naive human subjects. Med Sci Monit. 2003;9(9): 227-284.

17. Batt-Rawden BK. The benefits of self-selected music on health and well-being. The Arts in Psychotherapy. 2010;37: 301-310.

18. Beck AT, Steer RA, Garbin GM. Psychometric properties of the Beck Depression Inventory: Twentyfive years of evaluation. Clin Psychol Rev. 1988;8: 77-100.

19. Romito F, Lagattolla F, Costanzo C, Giotta F, Mattioli $V$. Music therapy and emotional expression during chemotherapy. How do breast cancer patient feel?". Eur J Integr Med. 2013;5: 438-442.

20. Matsuda T, Takayama T, Tashiro M, Nakamura Y, Ohashi $Y$, Shimozuma K. Mild cognitive impairment after adjuvant chemotherapy in breast cancer patient-evaluation of appropriate research design and methodology to measure symptoms. Breast Cancer. 2005;12(4): 279-287.

21. Merriman DJ, Diane AV, Miaskowski C, Aouizerat EB. Proposed mechanism for cancer and treatmentrelated cognitive changes. Semin Oncology Nursing. 2013;28(4): 206-269.

22. Nevid SF, Rathus AS, Greene B. Abnormal psychology. 2003; $5^{\text {th }}$ Ed. Jakarta: Erlangga.

23. Frold T, Schule C, Schmitt G. Association of brain derived neurotrophic factor vall66met polymorphisim with reduced hippocampal volumes in major depression. Arch Gen Psychiatry. 2007;64: 410-416.

24. Stahl SM, Wise DD. The potential role of corticotropinreleasing factor receptor-1 antagonist. Psychiatry. 2008;21(2): 106-111.

25. Hayama $Y$, Inoue $T$. The effect of deep breathing on "tensione anxiety" and fatique in cancer patient undergoing adjuvant chemotherapy. Complement Ther Clin Pract. 2011;XXX: 1-5.

26. Anjali J, Ulrich R. Sound control for improved outcome in health care settings. The Center for Health Design Issue Paper. 2007;4: 1-15.

27. Nilsson U. Soothing music can increase oxytocin level during bed rest after open-herat surgery: A randomised control trial. J Clin Nurs. 2009;18: 21542161.

28. Wilgram AL. The effect of vibroacoustic therapy on clinical and non-clinical population. London: St. Georges Hospital Medical School London University. 2002.

29. Campbell D. Music: Physician for time to come. $3^{\text {rd }}$ Edition. Wheaton: Qouest Books. 2006.

30. Chan MF, Chan EA, Mok E, Tse FYK. Effect of music on depression levels and physiological responses in community-based older adults. Int J Ment Health Nurs. 2009;18: 285-294. 
31. Chanda ML, Levitin DJ. Feature review: The neurochemestry of music. Trends in Cognitive Sciences. 2013;17(4): 179-193.

32. DeNora T. Music in everyday life. Cambridge: University Press. 2000

33. Roth EW. Music therapy: the rhythm of recovery. Case Manager. 2004.15: 52-56.

34. Nicholas, Humenick. How music works as a therapy. Jakarta: Salemba Medika. 2002.

35. Djohan. Music therapy: theory and aplication. Yogyakarta: Galang Press. 2006.

36. Atwater $\mathrm{H}$. Binaural Beats and the Regulation of Arousal Levels. Hemi-Sinc Journal. 2009;1: 1-2.
37. Guyton AC, Hall JE. The sense of deep hearing: Textbook of Medical Physiology, Eleventh Edition. 2007.

38. Rayes-Gibby CC, Anderson KO, Morrow PK, Shete S, Hassan S. Deppresive symptoms and health-related quality of life in breast cancer survivors. J Women Health. 2012;21(3): 311-328.

39. Wakim JH, Smith S, Guinn C. The efficacy of music therapy. J Perianesth Nurs. 2010;25(4): 226-232.

\section{Appendix}

Beck's Depression Inventory.

\section{Beck's Depression Inventory}

This depression inventory can be self-scored. The scoring scale is at the end of the questionnaire.

1.

$0 \quad$ I do not feel sad.

$1 \quad$ I feel sad

2 I am sad all the time and I can't snap out of it.

3 I am so sad and unhappy that I can't stand it.

2.

0 I am not particularly discouraged about the future.

1 I feel discouraged about the future.

2 I feel I have nothing to look forward to.

3 I feel the future is hopeless and that things cannot improve.

3.

$0 \quad$ I do not feel like a failure.

1 I feel I have failed more than the average person.

2 As I look back on my life, all I can see is a lot of failures.

3 I feel I am a complete failure as a person.

4.

$0 \quad$ I get as much satisfaction out of things as I used to.

1 I don't enjoy things the way I used to.

2 I don't get real satisfaction out of anything anymore.

3 I am dissatisfied or bored with everything.

5.

0 I don't feel particularly guilty

1 I feel guilty a good part of the time.

2 I feel quite guilty most of the time.

3 I feel guilty all of the time.

6.

$0 \quad$ I don't feel I am being punished.

1 I feel I may be punished.

2 I expect to be punished.

3 I feel I am being punished. 
7.

$0 \quad$ I don't feel disappointed in myself.

$1 \quad$ I am disappointed in myself.

$2 \quad$ I am disgusted with myself.

3 I hate myself.

8.

$0 \quad$ I don't feel I am any worse than anybody else.

1 I am critical of myself for my weaknesses or mistakes.

2 I blame myself all the time for my faults.

3 I blame myself for everything bad that happens.

9.

$0 \quad$ I don't have any thoughts of killing myself.

1 I have thoughts of killing myself, but I would not carry them out.

$2 \quad$ I would like to kill myself.

3 I would kill myself if I had the chance.

10.

I don't cry any more than usual.

I cry more now than I used to.

$2 \quad$ I cry all the time now.

3 I used to be able to cry, but now I can't cry even though I want to.

11.

$0 \quad$ I am no more irritated by things than I ever was.

1 I am slightly more irritated now than usual.

2 I am quite annoyed or irritated a good deal of the time.

3 I feel irritated all the time.

12.

$0 \quad$ I have not lost interest in other people.

1 I am less interested in other people than I used to be.

2 I have lost most of my interest in other people.

$3 \quad$ I have lost all of my interest in other people.

13.

$0 \quad$ I make decisions about as well as I ever could.

$1 \quad$ I put off making decisions more than I used to.

2 I have greater difficulty in making decisions more than I used to.

$3 \quad$ I can't make decisions at all anymore.

14.

$0 \quad$ I don't feel that I look any worse than I used to.

1 I am worried that I am looking old or unattractive.

2 I feel there are permanent changes in my appearance that make me look unattractive

3 I believe that I look ugly.

15.

$0 \quad$ I can work about as well as before.

$1 \quad$ It takes an extra effort to get started at doing something.

2 I have to push myself very hard to do anything.

$3 \quad$ I can't do any work at all. 
16.

$0 \quad$ I can sleep as well as usual.

$1 \quad$ I don't sleep as well as I used to.

2 I wake up 1-2 hours earlier than usual and find it hard to get back to sleep.

3 I wake up several hours earlier than I used to and cannot get back to sleep.

17.

$0 \quad$ I don't get more tired than usual.

$1 \quad$ I get tired more easily than I used to.

$2 \quad$ I get tired from doing almost anything.

3 I am too tired to do anything.

18.

My appetite is no worse than usual.

My appetite is not as good as it used to be.

$\begin{array}{ll}2 & \text { My appetite is much worse now. } \\ 3 & \text { I have no appetite at all anymore. }\end{array}$

19.

$0 \quad$ I haven't lost much weight, if any, lately.

$1 \quad$ I have lost more than five pounds.

$2 \quad$ I have lost more than ten pounds.

3 I have lost more than fifteen pounds.

20 .

$0 \quad$ I am no more worried about my health than usual.

1 I am worried about physical problems like aches, pains, upset stomach, or constipation.

2 I am very worried about physical problems and it's hard to think of much else.

3 I am so worried about my physical problems that I cannot think of anything else.

21.

I have not noticed any recent change in my interest in sex.

I am less interested in sex than I used to be.

I have almost no interest in sex.

I have lost interest in sex completely.

\section{INTERPRETING THE BECK DEPRESSION INVENTORY}

Now that you have completed the questionnaire, add up the score for each of the twenty-one questions by counting the number to the right of each question you marked. The highest possible total for the whole test would be sixty-three. This would mean you circled number three on all twenty-one questions. Since the lowest possible score for each question is zero, the lowest possible score for the test would be zero. This would mean you circles zero on each question. You can evaluate your depression according to the Table below.

Total Score Levels of Depression

$\begin{array}{ll}1-10 & \text { These ups and downs are considered normal } \\ 11-16 & \text { Mild mood disturbance } \\ 17-20 & \text { Borderline clinical depression } \\ 21-30 & \text { Moderate depression } \\ 31-40 & \text { Severe depression } \\ \text { over } 40 & \text { Extreme depression }\end{array}$

